Revista de la red interuniversitaria de estudios sobre las literaturas rioplatenses contemporáneas en Francia

$22 \mid 2021$

¿Cómo se cuenta una vida? El retorno de lo biográfico en la literatura rioplatense contemporánea

\title{
Un prisma. Silvina Ocampo por Mariana Enriquez
}

Un prisme. Silvina Ocampo par Mariana Enriquez

A prism. Silvina Ocampo by Mariana Enriquez

Judith Podlubne

\section{OpenEdition}

\section{Journals}

Edición electrónica

URL: http://journals.openedition.org/lirico/10801

DOI: 10.4000/lirico.10801

ISSN: 2262-8339

Editor

Réseau interuniversitaire d'étude des littératures contemporaines du Río de la Plata

Referencia electrónica

Judith Podlubne, «Un prisma. Silvina Ocampo por Mariana Enriquez», Cuadernos LIRICO [En línea], 22

2021, Publicado el 12 marzo 2021, consultado el 16 marzo 2021. URL: http://

journals.openedition.org/lirico/10801 ; DOI: https://doi.org/10.4000/lirico.10801

Este documento fue generado automáticamente el 16 marzo 2021.

\section{(c) () $\$ \Theta$}

Cuadernos LIRICO está distribuido bajo una Licencia Creative Commons Atribución-NoComercialSinDerivar 4.0 Internacional. 


\title{
Un prisma. Silvina Ocampo por Mariana Enriquez
}

\author{
Un prisme. Silvina Ocampo par Mariana Enriquez \\ A prism. Silvina Ocampo by Mariana Enriquez
}

Judith Podlubne

\section{Cambio de foco}

1 El 7 de agosto de 2003, mientras se desarrollaba en el auditorio del Museo de Arte Latinoamericano de Buenos Aires (MALBA) la segunda jornada del Homenaje a Silvina Ocampo (1903-2003), alguien del público, una mujer alta, elegante y de edad mediana, que hasta ese momento se confundía en la platea con el resto de los asistentes, interrumpió ofuscada los testimonios que algunos allegados a la escritora ofrecían desde el escenario. Las organizadoras del homenaje eran Nora Domínguez y Adriana Mancini. El programa, disponible en el sitio web del museo, permite reconstruir las circunstancias en detalle. Se trataba de la mesa de cierre, la coordinaba Mancini y entre los expositores estaban Dolores Bengolea, sobrina nieta de Ocampo, Juan José Hernández, Marcelo Pichon Rivière, Ernesto Schóo y Jorge Torres Zavaleta, amigos de distintas épocas. Hernández faltó con aviso de último momento. Debo haber estado esperándolo porque la decepción que me provocó saber que no llegaría es casi lo único que recupero con nitidez. Su convivencia con José Bianco, el otro escritor sobre el que yo investigaba en ese momento, me lo volvía atractivo por partida doble. Según lo recuerdo, los gritos de la mujer fortalecían los agravios a la homenajeada con elogios a su hermana: " $\mathrm{i}$ quién se le ocurre celebrar a alguien tan pérfido y egoísta como Silvina, en lugar de recordar a Victoria, siempre generosa!". No podría asegurar que los calificativos hayan sido estos, aún así diría que aciertan en el ánimo general de los reproches que esa descendiente de las Ocampo, según supe luego, lanzaba aquella tarde en la sala principal del MALBA.

2 Silvina Ocampo había muerto diez años antes, el martes 14 de diciembre de 1993. Además del centenario de su nacimiento, el homenaje conmemoraba ese aniversario. La 
puntualidad para morir contribuía a los números redondos. Sin mayores consecuencias que el malestar momentáneo que suscitó entre los presentes, la rudeza del episodio dio la pauta del furor que en 2003 la figura de Ocampo despertaba todavía entre quienes la habían frecuentado. Su muerte, en primera instancia, y la de su marido Adolfo Bioy Casares, un lustro más tarde, el lunes 8 de marzo de 1999, habían reactivado esas pasiones con la publicidad de testimonios nuevos, dispendiosos en anécdotas, chismes e infidencias, que subrayaban la excepcionalidad de la escritora y de su matrimonio.

Edgardo Cozarinsky, lector y amigo de Ocampo desde fines de los años sesenta, se ocupó de la relación entre chisme y excepcionalidad en "El relato indefendible", un texto clásico de 1973.

El chisme -escribió- se define como relato transmitido. Se cuenta algo de alguien y ese relato se transmite porque es excepcional el alguien o el algo: puede concebirse que se cuente una trivialidad de alguien famoso, o algo insólito de un desconocido; difícilmente, una trivialidad de un desconocido, y no es frecuente que coincidan el personaje famoso y el hecho insólito. (2005: 22)

4 En Silvina Ocampo la coincidencia parece sobredeterminada. Hija de una acaudalada familia patricia (la última de una serie de seis hermanas mujeres, cuya primogénita fue Victoria, fundadora y directora de la revista Sur), esposa de Bioy Casares, como apunté antes, amiga personal de Jorge Luis Borges, la historia de su vida resultó pródiga en circunstancias privilegiadas, que ambientaron sus relatos y poemas, pormenores estrafalarios, con los que sazonó cartas y entrevistas, y episodios privados, poco convencionales, cuyas razones mantuvo en reserva. Un aura legendaria envuelve a Silvina Ocampo. La rivalidad con Victoria distingue el capítulo fraterno de esa leyenda urdida con recuerdos de las protagonistas, versiones de los familiares, anécdotas de los amigos, de los amigos de amigos, y juicios de los detractores. Aunque el blanco favorito de las críticas fue Victoria, a mediados de los años 50, las Ocampo se transformaron en emblema de la oligarquía "imperialista", "extranjerizante" y "vendepatria" en nuestro país, según los términos que multiplicaron los adversarios de la izquierda nacional y el nacionalismo populista. La leyenda tiene un capítulo ideológico, virulento, del que Silvina es un personaje menos lateral de lo que se podría pensar si no se atendiera sólo a Victoria.

5 A su modo, candoroso y paradójico, Silvina Ocampo cumplió un papel importante en el armado de la leyenda que la tendría como protagonista tímida y recoleta. Sus relatos, poemas, cartas y entrevistas compusieron una imagen de sí que proveería motivos cardinales a la narración de su vida. Además de un dato biográfico, la minoridad -aludo aquí tanto a su atracción por lo infantil como a su tendencia al secreto, al fuera de foco o al segundo plano- resultó un asunto medular de su literatura y un rasgo distintivo de sus autofiguraciones. Ocampo acuñó fórmulas precisas, señas de identidad, económicas y eficaces, que sus lectores todavía repetimos con mayor asentimiento que distancia: "No soy sociable, soy íntima" (Ulla 1982: 42), "Prefería mantenerme del lado del secreto", "Nunca fui de grupos, me gustaba la soledad, guardaba las cosas para mí" (AAVV 1982: 361), "Me sentía el etcétera de la familia", "Hice todo a escondidas, a mí me gustaba esconderme" (Beccacece 1994: 113).

6 La escritura fue en su caso una elección tardía. Publicó su primer libro a los 34 años, había previsto dedicarse a la pintura. Impasible a los mandatos de la época, se transformó en una narradora soberana. La suya resultó obra de madurez que encontró en la infancia la manera absoluta de la ver las cosas, la invención de un mundo que lo inventaría todo de nuevo, incluidas las pautas con que debería ser leído. Así lo 
entendieron sus lectores iniciales entre fines de los años sesenta y comienzo de los setenta, Alejandra Pizarnik, Sylvia Molloy, Cozarinsky y Enrique Pezzoni, al encontrarse con La furia y otros cuentos (1959), Las invitadas (1961) y Los días de la noche (1971), los tres libros de relatos que tiempo después la catapultarían a una gloria discreta.

7 En los años 80, cuando la obra estaba próxima a cerrarse -Cornelia frente al espejo y Así sucesivamente, los últimos libros publicados en vida, son de 1987 y 1988-, la narrativa de Silvina Ocampo empezó a ser frecuentada por un público más amplio que el de los círculos cercanos. Los motivos de este desfasaje fueron razonados por la crítica. El reconocimiento literario de su obra coincidió con el pequeño suceso editorial que provocó la publicación de la autobiografía de su hermana Victoria, en la primera mitad de la década. Victoria había comenzado a escribirla en 1952, pero se negaría a publicarla antes de su muerte, ocurrida el 27 de enero de 1979. Los seis tomos de la autobiografía aparecieron entre 1979 y 1984 y se convirtieron de inmediato en best sellers. Los tres primeros, dedicados a la infancia, la adolescencia, la juventud y el amor clandestino con Julián Martínez, agotaron la edición en pocas semanas. Es probable que el interés masivo suscitado por estos volúmenes despertara expectativas sobre la narrativa y la vida de Silvina. Señalo esta coincidencia porque pone en evidencia otra que me importa especialmente. Me refiero a la identificación, entonces excluyente, entre la leyenda de las Ocampo y ese relato familiar de infancia que sus literaturas habían ido componiendo de modos diversos, en base a personajes, escenarios y tópicos compartidos: sirvientes, niñeras, institutrices extranjeras y tías en casonas y estancias de verano en las que gobierna la incuria de los adultos. Los vínculos filiales y fraternos de los miembros de las clases altas, sus usos y costumbres, delimitaron los núcleos principales de un relato biográfico común tramado en estos años. Fue el momento en el que las autofiguraciones de Silvina subrayaron su disposición al sigilo, al misterio, el espíritu reservado, frente a la expansividad y la determinación de Victoria.

Con la muerte de Silvina Ocampo, la leyenda cambió de foco y forma narrativa. Al incorporar los capítulos sobre el matrimonio y los hábitos sexuales, la novela familiar de infancia se transformó en melodrama sentimental, un género eminentemente masivo, con el que su narrativa había experimentado desde el comienzo y cuyos motivos y convenciones completaron en adelante el relato de su vida: amores clandestinos, triángulos amorosos, incesto, víctimas y victimarios, rivalidades, hijos extramatrimoniales reconocidos y no, muertes por accidente, decadencia económica, litigios judiciales. Debido en parte a las urgencias vitales y económicas de Bioy, la privacidad de Ocampo adquirió el estado público que ella le había negado. Se propagaron los rumores que durante años habían circulado como un secreto a voces. En 1981, Testimonio sobre Mariana, la novela en clave de Elena Garro, había dejado expuesta la relación amorosa que la autora mantuvo con Bioy durante décadas, estando ambos casados. Ella, con Octavio Paz, amigo de Bioy en ese momento. En 1983, el ensayo de Juan José Sebreli, "Historia secreta de los homosexuales en Buenos Aires", había sembrado dudas sobre las razones del matrimonio entre Ocampo y Bioy al registrar el rumor difundido por Arturito Álvarez sobre el romance de la escritora con Marta Casares, su suegra. La serie de textos autobiográficos que Bioy precipitó en el último tramo de su vida, la mayoría de los cuales se editaron en forma póstuma, explicitaron las cláusulas no escritas de ese "contrato matrimonial libérrimo" (Panesi 2000: 266) que los unió durante más de cincuenta años. Editadas en abril de 1994, cuatro meses después de la muerte de Ocampo, sus Memorias dieron por sobreentendidas las 
infidelidades conyugales y las mencionaron con un pudor todavía relativo, si se lo compara con el exhibicionismo gozoso y autosatisfecho de Descanso de caminantes, la miscelánea de brevedades autobiográficas, opiniones literarias y recuerdos personales publicada en 2001'. La jactancia da el tono de este libro en los momentos en que Bioy apunta las rutinas con sus "amigas" y las impresiones sobre ellas. La constante entre un volumen y otro, sostenida con matices hasta el Borges, aparecido en 2006, fue una imagen macilenta y mezquina de Ocampo, compuesta a partir del soslayamiento de su labor literaria y el acento en los roles de esposa demandante y torpe ama de casa.

Cuando en 1999 se estrenó "Las dependencias", el telefilm documental sobre Ocampo dirigido por Lucrecia Martel, a pedido de Lita Santic, con guión e investigación de Graciela Speranza y Mancini, el melodrama había dado ya uno de sus giros explícitos más abruptos. La publicación en 1998 de Correspondencia Pizarnik, a cargo de Ivonne Bordelois, había incluido algunas cartas a Ocampo, entre ellas, la fechada el 31 de enero de 1972, ocho meses antes del suicidio, en la que la poeta le declaraba un amor sin fondo. La relación de Ocampo con Pizarnik debía ser ya entonces relativamente conocida en el ambiente literario porteño para que, en 1975, una joven y enamoradiza María Moreno pudiera increparla con un "Yo soy más linda que Alejandra Pizarnik", ante la falta de respuesta a sus demandas amorosas ${ }^{2}$. El mayor de los muchos aciertos del documental de Martel fue dejar la narración a cargo de esas testigos únicas de la vida de Ocampo que resultaron Jovita Iglesias, el ama de llaves, y Elena Ivulich, la secretaria. Ambas frecuentaron a diario los multipisos de las calles Santa Fe y Ecuador, primero, y Posadas y Schiaffino, luego, durante más de cuatro décadas. Las declaraciones de Iglesias, sus memorias con la pareja, en particular con la escritora, fueron recogidas y editadas por Silvia Renée Arias en Los Bioy, publicado en 2001. Arias emparienta su libro con Monsieur Proust, el volumen que Céleste Albaret, el ama de llaves del novelista, escribió con ayuda de Georges Belmont y publicó en 1973³. El testimonio de Iglesias dio un impulso significativo al avance del melodrama ocampiano. Con un estilo simple, de claridad abismante, sus recuerdos iluminaron facetas inéditas de la escritora y mostraron un mundo doméstico, rutinario, de hábitos fijos y costumbres insólitas, asentado sobre un tembladeral de pasiones desbocadas y egoísmos sin calibre. La mezcla de dependencia afectiva e indiferencia flagrante caracteriza la atmósfera familiar en Los Bioy. Hasta la publicación del volumen, el desapego, la crueldad y los celos posesivos habían sido, para el público amplio, solo temas de la literatura de Ocampo. Iglesias no contó todo lo que sabía, pero sí más de lo que podía advertir. En una nota del 2002, Beccacece señaló que, así como Céleste Albaret se resistió a admitir que Proust hubiera tenido amores con hombres, Iglesias negó los amores lésbicos de Ocampo. Bastó apelar a la transparencia de sus dichos para que Beccacece pudiera probar su argumento: "Nunca vi nada en ese sentido. Venían a casa muchas amigas íntimas de la señora, pero yo nunca supe que ella tuviera esas mañas" (2002: 5. Subrayo yo).

En 2004, María Esther Vázquez dedicó al matrimonio el capítulo más extenso de su libro La memoria de los días. Mis amigos, los escritores. "Posadas 1650: Silvina Ocampo y Adolfo Bioy Casares: Con el número dos nace la pena" evoca con una nostalgia controlada, por momentos irónica, distintos episodios de su larga amistad. El texto comenta en detalles esa "trabazón obsesiva y enfermiza" que unía a la pareja, un lazo en el que "no se sabía quién dependía de quién" (2004: 136). Junto a los amoríos de Bioy, su mala fe, el fastidio ante los miedos y los controles de Ocampo, el dolor y la humillación de Ocampo, la complicidad y mutua displicencia, Vázquez registra esa dosis de sinrazón que 
finalmente sostendría el lazo entre ambos. La verosimilitud de su relato decrece cuando, con ánimo desafiante, la autora escatima contar los amores lésbicos de Ocampo, más aún, diría, cuando decide exhibir el escamoteo. "Mucho antes de su muerte, y aun hoy -escribe-, encuentro gente que maliciosamente me pregunta si Silvina Ocampo fue bisexual. No lo sé ni me parece importante saberlo" (134). Lo que su comentario no explica es para qué elige mencionarlo entonces.

11 La bisexualidad de Ocampo volvió a ser un tema implícito y secundario, al lado de otras revelaciones, en la entrevista que Dolores Bengolea le dio a la periodista Magdalena Ruiz Guiñazú en 2010 para el unitario televisivo "Las Ocampo" en el ciclo documental "Secretos de familia", que se emitía por el canal Todo Noticias. El melodrama había llegado a la televisión. El unitario está disponible en YouTube y la entrevista completa puede leerse en el libro homónimo que Ruiz Guiñazú publicó inmediatamente después del ciclo en la editorial Sudamericana. Queda claro que a Bengolea le interesa la veta más turbulenta de la leyenda. Cito un fragmento breve, que no le hace justicia al tono conclusivo de la entrevistada.

-Silvina era una persona muy tramposa, muy mentirosa, muy aprovechadora pero absolutamente querible. Era imposible no quererla, pero era mezquina, arbitraria, un poco ladina.

-No tuviste buena relación con ella.

-Sí, tuve muy buena relación con Silvina y la adoré, y la adoro, pero no dejo de ver

eso, sobre todo como contracara de Victoria, que era la generosidad (2010: 39).

La perfidia de Silvina versus la generosidad de Victoria, nuevamente. Dudo de mi memoria y pienso si no habría sido Bengolea la mujer de aquella tarde en el homenaje del MALBA. ¿Estaría en la platea y no en el escenario como indicaba el programa? ¿Sería otra descendiente de las Ocampo la que gritaba? ¿Quién, en ese caso? ¿Existía un acuerdo familiar en torno a la maldad y el egoísmo de Silvina? ¿Cómo se habría tramado? ¿Qué circunstancias, sucesos y entripados lo cimentarían? Podría comenzarse por conjeturar en torno a estos $u$ otros interrogantes si se busca remover el guion asentado en torno a su vida.

\section{Parte indivisible}

13 En 1991 Matilde Sánchez no podía imaginar la publicidad que alcanzaría la vida de Silvina Ocampo post mortem. Su prólogo a Las reglas del secreto, la voluminosa antología de cuentos que preparó para Fondo de Cultura Económica, pronosticó entonces que, dado el aislamiento de la escena cultural argentina en el que había vivido, "toda biografía de Ocampo habría de encontrarla no como una ayuda sino como un obstáculo. En los escasos testimonios que encuentre ese biógrafo hipotético -agregó- se topará con una deliberada ausencia de fechas, nombres y precisiones" (1991: 8). Publicada en 2014 por la Universidad Diego Portales de Santiago de Chile y reeditada en 2018 por la editorial Anagrama en Barcelona, La hermana menor. Un retrato de Silvina Ocampo, de Mariana Enriquez, es la primera biografía. El "biógrafo hipotético" resultó ser una escritora y los testimonios, abundantes y con más datos de los previstos. Se sabe la importancia que esta prioridad le otorga a los biógrafos: al establecer la versión inicial de una vida su relato será de consulta insoslayable.

"Vidas ajenas". En 2011, Enriquez había participado con un texto sobre Alejandra 
Pizarnik en Los malditos, la compilación de perfiles biográficos de escritores latinoamericanos del siglo XX que Guerriero había editado para la misma colección. El antecedente resulta doblemente relevante. Por un lado, porque la escritura de este perfil se proyecta sobre las decisiones formales y compositivas de La hermana menor y, por otro, porque la publicación de un texto biográfico sobre Pizarnik convoca de inmediato una escena de lectura exigente, eminentemente argentina, de la que la biografía de Ocampo participa por adyacencia. Me refiero a la escena que tiene sus coordenadas mayores en el ensayo y la biografía de Pizarnik escritos por César Aira. El primero, publicado en 1998 por Beatriz Viterbo Editora, reúne las cuatro charlas sobre la poeta que Aira dictó en el Centro Cultural Ricardo Rojas durante el mes de mayo de 1996. La biografía apareció en 2001 en la colección “Vidas literarias”, dirigida por Nuria Amat para Ediciones Omega en Barcelona. Ambos llevan por título el nombre Alejandra Pizarnik.

Enriquez se rehúsa a aceptar que La hermana menor sea una biografía: el subtítulo del volumen anuncia un retrato y sus entrevistas insisten en la idea de que es un perfil biográfico. El perfil es un género periodístico. Michael Holroyd recuerda que, aun cuando en la familia de la literatura la biografía se asume como el producto extraño del acoplamiento entre la historia y la novela tradicional, muchos sospechan que el verdadero padre fue el periodismo (2011: 39). El nombre inglés, profile, se le debe a Harold Ross y Jane Grant, los fundadores de la revista The New Yorker, y data de fines de los años veinte del siglo pasado. Los escritos sobre el género refieren a menudo a la experiencia de una práctica, pero no exploran la tradición en la que se sustenta esta forma, ni los problemas teóricos que compromete. Graduada en Periodismo y Comunicación Social, Enriquez se entrenó como escritora en el diario Página/12, donde se desempeña actualmente como subeditora del Suplemento Radar Libros. Tiene una obra narrativa premiada y traducida a varias lenguas, compuesta, hasta el momento, por cuatro novelas y tres libros de cuentos. En el prólogo a Los malditos, Guerriero, también destacada periodista de medios nacionales e internacionales, propone una definición ad hoc del género.

Un perfil. Un perfil no es un ensayo ni una crítica ni un análisis literario. Un perfil es un perfil es un perfil. Una mirada en primer plano sobre los trabajos y los días, los maridos y los hijos, los tíos y las bibliotecas, los armarios, los libros, los poemas, los viajes, los amantes, las manías, las píldoras, los electroshocks. (2017: 11)

La definición avanza por la negativa y retoma la idea desarrollada en su conferencia "La imprescindible visibilidad del ser, o la lección de Homero", leída en 2008 en el Festival Malpensante de Bogotá y compilada luego en Zona de obras del 2014 ${ }^{4}$. La fórmula que propone Guerriero, un perfil es una mirada, un punto de vista subjetivo, y las formas que su definición descarta, el ensayo y la crítica literaria, anticipan las decisiones y los recaudos de Enriquez sobre su trabajo.

Con Leila Guerriero, que editó el libro, no lo planteamos como una biografía sino como un perfil biográfico. No teníamos pretensión de totalidad. Leo bastantes biografías, pero para escribir esta leí vidas de escritores y personajes más segmentadas, porque la idea era una mirada antes que nada (Enriquez en Lezcano 2016: s/p. Subrayo yo).

El fantasma de la biografía retorna involuntario en el mismo momento en que se lo conjura. Los recaudos de Enriquez exponen los supuestos que avalan sus decisiones: la idea de que la "pretensión de totalidad" es una exigencia irrenunciable de la escritura biográfica y la confianza en una distinción nítida entre esta y las vidas de escritores. 
"La biógrafa cautelosa", el ensayo de Patricio Fontana incluido en Un arte vulnerable, examina con perspicacia la incomodidad de Enriquez ante el género y conjetura las razones que explicarían la actitud defensiva ante su libro. Para Fontana, la autora se muestra "intimidada, amedrentada" por la imposibilidad de acceder al archivo (2018: 211). Las 354 cajas que contienen parte importante de ese archivo, la biblioteca del matrimonio Ocampo-Bioy, estuvieron en custodia de Ernesto Montequin, el albacea, hasta el año 2017, año en el que fueron donadas a la Biblioteca Nacional, donde permanecen en proceso de catalogación. A diferencia de otras biografías, que se escriben contra las ya existentes de sus sujetos, La hermana menor, imagina Fontana, se habría construido a partir de esta imposibilidad, "bajo la sombra intimidante de un libro todavía inexistente: la biografía monumental que podría escribir Montequín o quien él decida" (2018: 199). Las declaraciones de Enriquez favorecen esta hipótesis. La hermana menor se compone sobre todo, pero no exclusivamente, a partir de los testimonios orales y escritos, que multiplicaron las muertes de Ocampo y de Bioy, y que los lectores argentinos fuimos consumiendo, como por entrega, a medida que el melodrama avanzaba. Enriquez consultó los reportajes disponibles, sumó entrevistas nuevas a amigos y conocidos de la escritora y convocó a otros entrevistados. El procedimiento es el mismo que había utilizado en el perfil de Pizarnik. Algunos de los testimonios obtenidos alcanzan a posteriori el valor agregado de ser los últimos que ofrecieron los convocados, quienes murieron al poco tiempo: María Esther Vázquez, Ernesto Schoó y Noemí Ulla.

19 Además de ponderar la importancia que reviste siempre una primera biografía, Benoît Peeters, el biógrafo de Jacques Derrida, propone, en divergencia con quienes defienden los beneficios de la distancia histórica, que el mejor momento para escribir una es el de los años posteriores a la muerte del biografiado, en los que se cuenta todavía con testigos próximos (2020: 82). La existencia de testimonios orales, el contacto directo con los amigos, parientes y conocidos del biografiado, distingue para Peeters las biografías frías de las calientes: "No me gustaría no tener más objeto que el papel; necesito los testimonios" (43). Presumo que Enriquez comparte esta preferencia. La hermana menor es una "biografía caliente". En Guerriero, la preferencia es explícita. Su conferencia del 2008, texto que describiría como programático de no ser porque esquiva todas las prescripciones, otorga una importancia central a la entrevista en la elaboración del perfil. El arte del entrevistador combina, según especifica, el de hacer preguntas con el de saber mirar. Mirar lo que alguien hace diría de sí mismo mucho más de lo que cualquiera está dispuesto a admitir. Enriquez domina ambas artes. No descartaría entonces que el impedimento de acceder al archivo, sin dudas un obstáculo para cualquiera que decida emprender el relato de una vida, haya tenido, en su caso, la ventaja compensatoria de haberle permitido realizar lo que efectivamente se había propuesto desde un comienzo: escribir un retrato o un perfil, es decir, variantes de la forma biográfica definidas por el derecho a la parcialidad, a la visión personal sobre el biografiado, cuyos antecedentes remiten, cuanto menos, a Victorianos eminentes de Lytton Strachey.

20 ¿A qué obedecería entonces la actitud cautelosa que Fontana había percibido en la escritura de Enriquez? ¿Qué la intimidaría si la presión de la biografía monumental quedaba, de hecho, neutralizada por la falta de acceso al archivo y, de derecho, porque las tareas de indagación exhaustiva de ese material no parecían haber sido su propósito? Toda biografía muestra también el estado del saber disponible sobre el 
biografiado en el momento en que se escribe. Pero no porque incorporarlo constituya un requisito indeclinable del género -muchas y excelentes biografías apuestan a la selección: tal es la enseñanza de Strachey- sino porque el biógrafo escribe en conversación con ese estado. La hermana menor da cuenta de los núcleos argumentales más significativos (y exacerbados) de la leyenda de Ocampo a partir de las distintas versiones orales y escritas que ofrecieron los testigos. La vertiente melodramática alcanza una prioridad notable sobre la del relato de infancia: de las 211 páginas del libro, sólo las primeras 28 están dedicadas a los años previos al matrimonio con Bioy. La proporción es curiosa si se considera la insistencia con que Silvina recuerda su infancia en las entrevistas, la gravitación que tiene en su literatura y el hecho adicional de que el primer tomo de la autobiografía de Victoria ofrece, como apunté arriba, una cantidad de información atractiva sobre la vida familiar. De las 183 páginas restantes, no más de 30 se ocupan de la obra. Enriquez articula un relato cronológico y plurívoco hilvanando los "jirones de biografía" (la fórmula le pertenece) que, de modo disperso, ya estaban disponibles. En un reportaje con Nuria Azancot, lo cuenta de este modo: "Elegí una polifonía: muchas voces de distintas fuentes cuentan su versión de Silvina, la Silvina que conocieron (o sobre la que escribieron, cuando usé fuentes escritas). No siempre coinciden y elegí mantener ese prisma" (2018: 1). "Reina, madrina, Victoria" es un parágrafo emblemático en este sentido porque expone, sin resolver, las tres alternativas que explicarían el distanciamiento entre las hermanas: la variante cándida, la que involucra aspectos de política literaria y traición, y la brutal, teñida de abuso sexual e incesto. "Menos que una mirada, acierta Fontana, este retrato presenta una miríada de miradas sobre Silvina Ocampo; una miríada de miradas que ayuda a apuntalar la idea de misterio..." (2018: 201) que cifra la vida de la escritora.

Desde el título, la imagen de Silvina Ocampo que ofrece La hermana menor ratifica, sin interrogar, lo que los lectores argentinos conocíamos desde hace tiempo. El libro extiende la leyenda ocampiana a un público internacional, hispanoparlante y contemporáneo, interesado en vidas femeninas. "Preferí dejar sentado el mito", afirma Enriquez en la entrevista con Patricio Zunini, "lo que me parece más interesante porque no es una investigación policial. Me cerraba más que ir desesperadamente detrás de los hechos para saber qué era cierto" (2014: 2). La alternativa que plantea su comentario reduce el ejercicio biográfico a dos recursos igualmente módicos: el respeto, la reproducción, de los lugares comunes que fortalecen el mito del biografiado (¿qué sería si no "dejar sentado"?) o el develamiento de los secretos que podrían refutarlo. Esta segunda opción es la que se anuncia desde la contratapa sin firma que comparten las ediciones chilena y española. "En este libro, la escritora argentina Mariana Enriquez, a través de una enorme cantidad de fuentes bibliográficas y testimonios de amigos, críticos, parientes y albaceas de Silvina Ocampo, cuestiona los mitos, descorre el velo sobre los secretos y...". En ambos casos, cuando el sujeto en cuestión es un escritor o un artista, el efecto que se produce es el mismo: la obra del biografiado queda relegada a un interés subsidiario y el vínculo que esta establece con su vida resigna todo espesor problemático.

El tema central de las biografías de escritores -razona Analía Capdevila- es la relación entre la vida y la obra. Y si bien el género se encuentra fuertemente codificado -se repiten muchos tópicos y motivos en las versiones más estandarizadas-, lo que atenta contra toda originalidad no es esa prescripción, sino más bien el modo en el que se postula en cada oportunidad (en cada autor) el problema central que lo estructura, que está en la base como su fundamento; allí es donde se asegurara el éxito o el fracaso de la biografía. (2018: 213) 


\section{biográfico de la formas propias de la crítica literaria, pero no menos cierta que esta} distinción es la que se establece entre el perfil de un escritor, un artista, y el de cualquier otro sujeto biografiable. En la vida de un escritor, al menos, en la vida de uno escrita por otro, y pienso exclusivamente en las que cumplen esta doble condición, ni los amantes ni las manías, ni los viajes, ni los electroshocks, por mencionar algunos de los atributos que enumera Guerriero, significan en sí mismos. Ellos valen menos por lo que efectivamente fueron (en el caso de que ese valor pudiese establecerse de algún modo) que por la irrealidad a la que la escritura de la obra los devuelve para que puedan seguir significando en el futuro. La vida no está en el origen de la obra, enseña Barthes (1987: 79), sino que es una fábula concurrente con ella, hay una reversión de la obra sobre la vida (y no al contrario); es la obra de Proust, de Genet, agrega, lo que permite leer su vida como un texto. El perfil o la biografía de un escritor -la distinción es, en este punto, plenamente irrelevante- requiere de un pensamiento sobre el vínculo entre vida y obra, en lo fundamental, para sortear la tentación sustancializadora que amenaza a ambas y así mantener vivo el movimiento de (y entre) una y otra.

El biógrafo se sienta a escribir una vida, señala Matías Serra Bradford, no para iluminar una obra (esto es un efecto secundario) sino para retratar la relación (un relato aparte) entre obra y vida, a veces antagónicas, precisamente, para que cada una pueda sobrevivir por su cuenta. Lo que un biógrafo juzga es, entre otras cosas, si una vida posee un misterio lo suficientemente magnético, y si la obra es parte indivisible de ese misterio. (2011: 12)

Narrada por Enriquez, la vida de Ocampo resulta una colección de acontecimientos públicos y privados articulados con el fin de subrayar la peculiaridad de la protagonista. La obra tiene un lugar recortado en esta historia. Uno menos relevante que sus dotes de adivina, sus romances, los de Bioy, sus temores, su tacañería, si se atiende al modo en el que la narración biográfica presenta cada uno de estos rasgos. $L a$ hermana menor dedica un parágrafo breve ( 3 páginas promedio) a cada libro de cuentos de Ocampo. En pocas ocasiones remite a la poesía y los libros para niños se subsumen a la maternidad de la autora. "Cuando empezó a criar a su hija, también comenzó a escribir cuentos para chicos" (2014: 100). En "Florecían rulos de sangre", la biógrafa se ocupa de Viaje olvidado, publicado en 1937; en "La imaginación rigurosa", de Autobiografía de Irene, de 1948; en "Como para no estar muerta con este día", de La furia, de 1959; en "Las cosas más maravillosas y las cosas más terribles del mundo", de Las invitadas, de 1961; en "Ladrona en sueños", de Los días de la noche, de 1970; en "Siempre jugué a ser lo que no soy" de Y así sucesivamente y Cornelia frente al espejo, de 1987 y 1988, respectivamente. La presentación de la obra replica el registro cronológico que guía el relato de la vida y se intercala entre sus acontecimientos. En todos los casos, la estructura de los parágrafos combina un acercamiento temático a los cuentos, la identificación de personajes, tópicos y procedimientos recurrentes, con extensas valoraciones específicas de lectores especializados. Enriquez no ofrece una visión de conjunto sobre la literatura de Ocampo, rara vez arriesga un juicio propio, se precave de derivar la obra de la vida y sólo en las contadas ocasiones en que refiere sucesos autobiográficos se permite conexiones directas entre una y otra. Por momentos, demasiado directas, si pienso, por ejemplo, en la analogía sin resto que propone entre la autora y la protagonista de "El pecado mortal". "Y la propia Silvina, la Muñeca de "El pecado mortal”, que conoce el sexo antes de la primera comunión" (2014: 118).

Cuadernos LIRICO, 22 | 2021 
24 A los parágrafos sobre cada libro, La hermana menor añade otro, extenso y general, "Mi vida no tiene nada que ver con lo que escribo", que recoge la discusión sobre la recepción de la obra en vida de Ocampo. Enriquez se interesa por dilucidar si Ocampo fue leída o no por los contemporáneos, una contienda saldada en los estudios especializados, que, además, indagan cómo se la leyó en cada momento. Basta recordar que se trata de una narrativa que se publicó a lo largo de las cinco décadas centrales del siglo XX, un período de marcadas transformaciones en los modos de leer especializados de la crítica argentina, y también del público amplio, para advertir que resulta imposible evaluar los encuentros y desencuentros con sus lectores al margen de esas transformaciones. La evaluación requiere un ejercicio interpretativo del que La hermana menor prescinde para cumplir su propósito. "Hay mucho escrito académicamente sobre Silvina, señala la autora, pero no tanto, desde un perfil más accesible, y eso me daba un poco de ganas" (Zunini 2014: 1). Está claro que no es una biografía académica. Aun así, como señalé antes, los críticos son una referencia habitual en los momentos dedicados a la obra. Enriquez los lee, los entrevista y los cita extensamente; se diría que deja la perspectiva sobre la obra en sus manos. Incluso en las ocasiones en que se la consulta sobre posibles afinidades entre su literatura y la de Ocampo, se cuida de opinar sobre ella y desestima toda procedencia deliberada. "Supongo que hay un aire de familia entre ella y yo. Si tengo que decir concientemente de dónde salieron mis niños y adolescentes, digo sin dudar: de Stephen King... Pero quizá, por genética rioplatense, sean también los de Silvina Ocampo. $O$ un híbrido anfibio" (Azancot 2018: 1). La filiación directa de su literatura con la de Ocampo la incomoda. No es una escritora a la que admire particularmente, no la relee a menudo, no la conocía demasiado antes de encarar la biografía. Aceptó escribirla, según cuenta, por fidelidad a un remoto recuerdo infantil: la existencia de un ejemplar de El pecado mortal, la antología de Centro Editor de América Latina, en la biblioteca de sus padres. Sus declaraciones son precisas y honestas en este sentido. En ocasiones, incluso, siente la necesidad (en varias direcciones, innecesaria) de explicitar su falta de formación en crítica literaria. "De Silvina hay muchísimo escrito, señala, hay mucha crítica literaria académica muy dura, muy difícil. Más que nada porque yo no estoy formada así. De todos modos, lo leí todo, hablé con algunos y a otros los cito porque los leí" (Enriquez en Toutonian 2018: 3). Un argumento más en favor de la posición cautelosa identificada por Fontana, quien había advertido ya el peso que sobre la autora ejerce el dictum de la teoría literaria que sanciona la lectura biográfica de la literatura.

La distancia, la exterioridad, que Enriquez mantiene con la obra de Ocampo debilita la escritura biográfica. Sus competencias y expectativas periodísticas se muestran incompatibles con la sofisticación pavorosa, la sutileza extrema, de estas narraciones. Pareciera que no saben qué hacer con ellas y no hacen nada. Diría entonces que la cautela de Enriquez es, ante todo, índice de la sospecha, si no del reconocimiento, de que a La hermana menor le falta ese relato aparte entre obra y vida que Serra Bradford identificó con la tarea fundamental del biógrafo escritor. Un relato que en el tejido de la literatura argentina encuentra realizaciones magistrales en las obras de Jorge Luis Borges y César Aira, además de una formulación exacta en la idea del "mito personal del escritor", que propuso este último. La leyenda, el mito a secas, escribe Aira, próximo a aquella definición de chisme en Cozarinsky, es el cuento que todos conocen y que nadie se cansa de oír otra vez. Pero la idea del "mito personal del artista" no se confunde con la de "mito a secas", aunque se desprenda de ella. Para Aira, los artistas encarnan una forma particular del mito porque la máquina mitificadora no afecta al 
"mero escritor como sujeto biográfico, sino al complejo que forma su vida y su obra, su fórmula, su estilo". Lo que en otro lugar llamará "procedimiento". La noción de "procedimiento", cuyo mérito y utilidad de primer orden radicaría en librar a la literatura de la psicología del sujeto, es lo que impide que la leyenda del escritor se solape con su mito personal. Y esto, explica Aira, porque:

[...] en un artista, la repetición inherente al mito pasa a otro nivel y se manifiesta como una inventiva constante. La invención deja de ser causa de lo inventado, donde se consumaría desapareciendo, para transformarse en un continuo de invención de la invención que es en adelante la vida del artista. (1991:49)

El mito personal del escritor es el relato de la vida artística, o mejor, el hacerse artística de la vida en el relato. La impersonalidad, el motor del continuo. Conviene releer el extenso rodeo en torno a la palabra "sujeto" que Aira incrusta en el corazón de su ensayo sobre Alejandra Pizarnik (1998: 59-63), un auténtico meteorito contra las convenciones del género biográfico en el ensayo sobre la autora a la que le dedicará una biografía, para advertir que la idea de mito personal realiza la destitución del sujeto y afirma, en su lugar, la supervivencia de la vida en el arte. Se trata de la transmutación de la vida (subjetiva) en vida (impersonal) -"el devenir de la vida en vida", "la vida que se transforma en vida", en palabras de Aira- por obra del continuo de invención de la invención que inaugura la escritura. Al mito personal del escritor lo cuenta su escritura, por eso es siempre un mito de origen: el relato de cómo cada vez se hace escritor y no la ficción autobiográfica de cómo llegó a serlo. A la leyenda, en cambio, como al chisme, la cuentan y la repiten los otros, incluso cuando en ocasiones sea el propio autor quien la acuñe y propague. En la obra, el escritor revive a lo largo de su vida el origen: el momento de invención de lo nuevo; la vida del escritor, y también la de la obra, dependen de ese mito de origen. Ser escritor es "una creencia en suspenso". La idea del mito personal desbiografiza la leyenda del escritor y hace del mito de origen de la escritura el corazón opaco de la empresa biográfica. Sólo a partir de este trastocamiento, el misterio de la vida del artista resulta lo suficientemente magnético, por indescifrable, y la obra se torna parte indivisible, y necesaria, del mismo.

\section{BIBLIOGRAFÍA}

AAVV, "Silvina Ocampo", Encuesta de la literatura argentina contemporánea, Capítulo 143, Buenos Aires, Centro Editor de América Latina, 1982.

Aira, César, Alejandra Pizarnik (1936-1972), Barcelona, Ediciones Omega, 2001.

---, Alejandra Pizarnik, Rosario, Beatriz Viterbo Editora, 1998.

---, Copi, Rosario, Beatriz Viterbo Editora, 1991.

Azancot, Nuria, “Mariana Enriquez: Silvina Ocampo quería ser secreta, mantener el misterio”, El Cultural.es, 2018, Web. Consultado el 16 de diciembre de 2020.

Barthes, Roland, “De la obra al texto", El susurro del lenguaje, Barcelona, Paidós, 1987. Traducción de C. Fernández Medrano. 
Beccacece, Hugo, “Los Bioy. La guardiana de los secretos”, La Nación. Suplemento Cultura, 2002, Web. Consultado el 16 de diciembre de 2020.

---, “Silvina Ocampo", La pereza del príncipe, Buenos Aires, Editorial Sudamericana, 1994.

Bordelois, Ivonne, Correspondencia Pizarnik, Buenos Aires, Seix Barral, 1998.

Capdevila, Analía, “El mito personal del escritor. César Aira y Alejandra Pizarnik", Nora Avaro, Julia Musitano y Judith Podlubne (ed.), Un arte vulnerable. La biografía como forma, Rosario, Nube Negra, 2018.

Catelli, Nora, "Dos hombres solos hablan: Borges de Bioy Casares", Variaciones Borges 34, 2012, p. 27-37.

----, “Adolfo Bioy Casares: Memorialista, diarista y retratista americano", Políticas de la Memoria 17, 2017, Web. Consultado el 16 de diciembre de 2020.

Cozarinsky, Edgardo, "El relato indefendible", Museo del chisme, Buenos Aires, Emecé Editores, 2005.

Enriquez, Mariana, La hermana menor. Un retrato de Silvina Ocampo, Colección Vidas ajenas, Universidad Diego Portales, Santiago de Chile, 2014.

Fontana, Patricio, "La biógrafa cautelosa. Mariana Enriquez retrata a Silvina Ocampo", Nora Avaro, Julia Musitano y Judith Podlubne (ed.), Un arte vulnerable. La biografía como forma, Rosario, Nube Negra, 2018.

Giordano, Alberto,"La intimidad de un hombre simple: los escritos autobiográficos de Adolfo Bioy Casares", Cuadernos LIRICO, 1, 2006, Web. Consultado el 16 de diciembre de 2020.

Guerriero, Leila, “Prólogo”, Los malditos, Santiago de Chile, Universidad Diego Portales, 2011.

---, "La imprescindible invisibilidad del ser, o la lección de Homero", Zona de obras, Madrid, Círculo de tiza, 2014.

Holroyd, Michel, “¿Qué justifica la biografía?”, Cómo se escribe una vida. Ensayos sobre biografías, autobiografías y otras aficiones literarias, Buenos Aires, La bestia equilátera, 2011, p. 39-52. Traducción de Laura Wittner.

Lezcano, Walter, "De Silvina Ocampo a Osvaldo Lamborghini: las mejores biografías de escritores", La Nación, Suplemento Ideas, 3 de agosto de 2016, Web. Consultado el 16 de diciembre de 2020.

Panesi, Jorge, "Bioy Casares: el amor del estanciero", Críticas, Buenos Aires, Norma Editorial, 2000, p. 263-268.

Peeters, Benoit, Tres años con Derrida. Los cuadernos de un biógrafo, Buenos Aires, Ubú Ediciones, 2020. Traducción de Vicente Tuset.

Ruiz Guiñazú, Magdalena, “Las Ocampo”, Secretos de familia, Buenos Aires, Sudamericana, 2010.

Sánchez, Matilde, "Prólogo", Las reglas del secreto, Buenos Aires, Fondo de Cultura Económica, 1991.

Serra Bradford, Matías, "La perfección de la vida. Una visita a Michael Holroyd”, Michael Holroyd, Cómo se escribe una vida. Ensayos sobre biografías, autobiografías y otras aficiones literarias, Buenos Aires, La bestia equilátera, 2011, p. 9-21. Traducción de Laura Wittner.

Ulla, Noemí, Encuentros con Silvina Ocampo, Buenos Aires, Editorial Belgrano, 1982. 
Toutonian, Lala, “Silvina tenía a todos fascinados", Entrevista con Mariana Enriquez, Blog Eterna Cadencia, 14 de agosto de 2018, Web. Consultado el 16 de diciembre de 2020.

Vázquez, María Esther: “Posadas 1650: Silvina Ocampo y Adolfo Bioy Casares: Con el número dos nace la pena", La memoria de los días. Mis amigos, los escritores, Buenos Aires, Emecé Editores, 2004, p.73-150

Zunini, Patricio, "Silvina en la bruma. Mariana Enriquez habla de La hermana menor. Un retrato de Silvina Ocampo", Blog Eterna Cadencia, 4 de julio de 2014, Web. Consultado el 16 de diciembre de 2020.

\section{NOTAS}

1. Sobre estos libros de Bioy Casares, consultar los ensayos de Panesi (2000), Giordano (2006) y Catelli (2012 y 2017).

2. La anécdota introduce la entrevista publicada originalmente en El Cronista Cultural del 13 de septiembre de 1975 e incluida en 2005 en Vida de vivos. Conversaciones incidentales y retratos sin retocar (Buenos Aires, Sudamericana). "En esa época, la exageración y las relaciones prohibidas eran bien vistas. La entrevista duró cinco meses. Ella no cesaba de corregirla; yo, de ir a su casa con cualquier pretexto. Me le declaré. Me preguntó qué quería decir exactamente o, mejor dicho, exactamente qué quería hacer. Yo no tenía idea. Ella sonrió y dijo: "Sufro del corazón". "Yo soy más linda que Alejandra Pizarnik", le contesté y me fui dando un portazo. La ceguera de la timidez puede convertirse en audacia" (2005: 70).

3. En 2005, Los Bioy encontró un libro gemelo en El señor Borges, el retrato que Epifanía Uveda (Fanny), el ama de llaves del escritor, compuso junto a Alejandro Vaccaro. En 2020, se publicó El último Bioy, el libro que Lidia Benítez, asistente y enfermera de Bioy durante su última década, escribió en colaboración con Javier Fernández Paupy. Reservo para otra ocasión la lectura conjunta de esta serie biográfica.

4. “Un perfil -apunta en esa oportunidad- no es la mirada de la mamá, el hermano, la novia o el novio del entrevistado. Un perfil no es lo que el entrevistado escribiría sobre sí porque ese género ya existe y se llama autobiografía. Un perfil es, por definición, la mirada de otro. Y esa mirada es, siempre, subjetiva. Donde subjetiva no quiere decir artera, donde subjetiva no quiere decir vil, donde subjetiva no quiere decir miserable. Donde subjetiva quiere decir la mirada de una persona que cuenta lo que ve o lo que, honestamente, cree ver" (2014: 219).

\section{RESÚMENES}

El artículo propone una lectura de La hermana menor. Un retrato de Silvina Ocampo de Mariana Enriquez. Comienza por reconstruir y analizar la forma en que se trama la leyenda de Ocampo en los años 80 y el cambio de foco que esta leyenda experimenta a partir de su muerte. Examina luego qué hace Enriquez con este saber disponible (qué selecciona, qué agrega, cómo lo articula), conjetura sobre las razones por las que insiste en afirmar que escribió un perfil y no una biografía, y reflexiona sobre el lugar que la narración de la vida le otorga a la obra de Ocampo. 
Cet article propose une lecture de La hermana menor. Un retrato de Silvina Ocampo par Mariana Enriquez. Il commence par reconstruire et analyser la manière dont se tisse la légende d'Ocampo dans les années 80 et le changement d'orientation que connait cette légende après sa mort. Il examine ensuite ce qu'Enriquez fait de ces connaissances disponibles (ce qu'elle sélectionne, ce qu'elle ajoute, comment elle l'articule), spécule sur les raisons pour lesquelles elle insiste pour prétendre qu'elle a écrit un profil et non une biographie, et réfléchit à la place que le récit de vie donne à l'œuvre d'Ocampo.

The article proposes a reading of La hermana menor. Un retrato de Silvina Ocampo by Mariana Enriquez. It begins by reconstructing and analyzing how the legend of the writer is plotted in the 80 's and the change of focus that this legend experiences since her death. It examines what Enriquez does with this knowledge (what she selects, what she adds, how she articulates it), conjectures about the reasons why the biographer insists on stating that she wrote a profile and not a biography, and reflects on the place that the narration of life grants Ocampo's work.

\section{ÍNDICE}

Mots-clés: biographie, profil biographique, vie, travail

Keywords: biography, biographical profile, life, work

Palabras claves: biografía, perfil biográfico, vida, obra

\section{AUTOR}

\section{JUDITH PODLUBNE}

IECH, UNR - CONICET

judithpodlubne@gmail.com 